\section{Secretion of immunomodulat- ing neuropeptides (VIP, SP) and nitric oxide synthase in porcine small intestine during postnatal development}

\author{
A. Kovšca Janjatović, ${ }^{1}$ H. Valpotić, ${ }^{1}$ \\ D. Kezić, ${ }^{1}$ G. Lacković, ${ }^{2}$ G. Gregorović, ${ }^{2}$ \\ S. Sladoljev, ${ }^{3}$ G. Mršić, ${ }^{4}$ M. Popović, ${ }^{1}$ \\ I. Valpotić1
}

${ }^{1}$ Veterinary Faculty, University of Zagreb;

${ }^{2}$ Faculty of Science, University of Zagreb;

IInstitute of Immunology, Zagreb;

${ }^{4}$ Center for Forensic Investigations,

Research and Expertise Ivan Vučetić,

Zagreb, Croatia

\section{Abstract}

Immunohistological identification/localization of immunomodulating neuropeptides [vasoactive intestinal polypeptide (VIP) and substance $\mathrm{P}$ (SP)] and enzyme nitric oxide synthase (NOS) as well as histomorphometric analyses of kinetics of their release and development of respective nerve fibers density during postnatal ontogenesis of porcine intestinal mucosal immune system (IMIS), were performed in order to assess the role of these molecules involved in maturation of the IMIS. The kinetcs of reactions to VIP, SP and NOS were demonstrated in the samples of jejunum and ileum from conventionally reared pigs. The samples were obtained at $0,7,14,21,28,35,42$ and 49 days of age and processed for immunohistological staining. The $\mathrm{VIP}^{+}$reaction was prevalently visible in the epithelial layer, lamina propria and Lieberkühn crypts (Lc) but also in the submucosa and lamina muscularis along blood and lymphatic vessels. The $\mathrm{SP}^{+}$ fibers were regularly distributed along enteric neurons in the muscular layer. The reaction to NOS was demonstrated in both mucosa and submucosa of ileum and jejunum and in the ileal Peyer's patches (PP). Intensity of the reaction was more pronounced in the epithelial layer and numerous $\mathrm{NOS}^{+}$cells were observed around the Lc and inside the follicles of the PP. Also, we have noticed $\mathrm{NOS}^{+}$blood vessels, particular neurons and nerve fibers in the submucosa and muscular layer of the small intestine. By analyzing quantitative patterns of $\mathrm{SP}^{+}, \mathrm{VIP}^{+}$fibers and release of NOS we have concluded that intensity of their reactions gradually increases with age, except a short period of stagnation after weaning (at age of 28 days), reaching the highest values in the pigs aged between 42 and 49 days. The values obtained by Sperman rank order correlation test (rs) between days of age of pigs and intensity of the reactions in their jejunum/ileum to VIP $\left(r_{s}=0.97 / 0.95\right), S P\left(r_{s}=0.97 / 0.97\right)$ and NOS $\left(r_{s}=0.98 / 0.95\right)$, respectively, showed positive correlations $(\mathrm{P}<0.05)$ according to Roemer Orphal scale. Current study showed that postnatal development of porcine IMIS was accompanied by a substantial increase in the secretion of neuropeptides/enzyme tested and that these molecules may participate in the functional maturation of immunoregulatory/bactericidal mechanisms of the local (intestinal) immune defense in young pigs.

\section{Introduction}

The swine is an important model in biomedical research for studying developmental immunology, particularly of the intestinal mucosal immune system (IMIS), due its omnivorous gut physiology and morphology which are rather comparable to those in humans than in rodents. ${ }^{1}$ It is less known that the IMIS comprising disperse and aggregated immune cells is the largest part of a general immune system protecting the organism against gut microbes and their products. However, it is well known that such responsiveness either physiological or pathological is regulated by bidirectional interaction between neuroendocrine and immune systems. ${ }^{2,3}$

Namely, the small intestine possesses a network of nerve fibers that contains vasoactive intestinal polypeptide (VIP). This neuropeptide is also produced by lymphoid cells and exerts a wide variety of immunological functions, including control of homeostasis of the immune system by ligand-receptor signaling to immunocompetent cells, regulation of the production of anti- or pro-inflammatory mediators, changing of the expression of co-stimulatory molecules leading to switching of Th1 to Th2 response, and stimulation of B cell differentiation and production of IgA antibodies. ${ }^{4,5}$ Anti-inflammatory effect of VIP is ascribed to its ability to abrogate phagocytosis and chemotaxis of macrophages ${ }^{6}$ and to inhibit T cell proliferation and migration. ${ }^{7}$ It has been shown that VIP may also suppress the release of proinflammatory cytokines such as TNF $\alpha$, IFN $\gamma$, IL-6 and IL-12, ${ }^{8-11}$ decrease production of inducible nitric oxide synthase (NOS) ${ }^{8}$ and increase production of anti-inflammatory cytokines such as IL-10 and IL-1Ra. ${ }^{12,13}$ Porcine VIP has been isolated from duodenum ${ }^{14}$ which implies that this neuropeptide is released by neurons residing the small intestinal network of nerve fibers, stretching in all mucosal/submucosal layers, particularly within Peyer's patches (PP), similarly as described in rat. ${ }^{15}$
Correspondence: Prof. Ivica Valpotić,

Department of Biology, Veterinary Faculty, University of Zagreb, Heinzelova 55, 10000 Zagreb, Croatia.

Tel. +385.1.2390144 - Fax: +385.1.2441.390

E-mail:valpotic@vef.hr

Key words: postnatal ontogenesis, small intestine, immunomodulating molecules (VIP, SP and NOS), pig.

Acknowledgements: the current study was supported by the grant no. 053-0532265-2255 from the Ministry of Science, Education and Sport of Croatia.

The excellent technical assistance of Mrs. Zrinka Benčina is gratefully acknowledged.

Received for publication: 15 January 2012. Accepted for publication: 15 May 2012.

This work is licensed under a Creative Commons Attribution NonCommercial 3.0 License (CC BYNC 3.0).

(C) Copyright A.K. Janjatović et al., 2012

Licensee PAGEPress, Italy

European Journal of Histochemistry 2012; 56:e30 doi:10.4081/ejh.2012.e30

The substance P (SP) was initially recognized as an agent that promotes contraction of ileal smooth muscles and acts as neurotransmitter of pain. ${ }^{16}$ Besides brain its concentration is the highest in intestines. Nerve fibers that contain SP represent the main component of the intestinal nerve system and participate in regulation of the immune functions ${ }^{17-19}$ by acting through different immune and inflammatory cells, such as mast cells, macrophages, $\mathrm{T}$ and $\mathrm{B}$ lymphocytes and $\operatorname{Ig} \mathrm{A}^{+}$plasma cells..$^{20-25}$ Stimulatory effect of SP in the porcine jejunum has been demonstrated both via a direct pathway where terminal nerve endings release SP and via an indirect way with SP stimulating cholinergic neural pathways. ${ }^{26,27}$ The SP-mediated activation of immune and inflammatory cells provides release of cytokines during the course of inflammation associated with diarrheal disease. ${ }^{28}$

Nitric oxide (NO) is a non-adrenergic noncholinergic neurotransmitter in the enteric nervous system and also plays an important role in the regulation of blood pressure, smooth muscle activity and intestinal motility as well as in modulation of the immune and inflammatory reactions..$^{29,30}$ The neurons expressing NO were found to be present in porcine and human intestines. ${ }^{31,32}$ The NO is generated intracellularly by NOS and enterocytes may also express an inducible form of NOS providing production of the NO. ${ }^{33}$ Such production of the NO may be stimulated by pro- 
inflammatory cytokines or bacterial lypopolysaccharides, ${ }^{33,34}$ which enhances migration of lymphocytes to the lamina propria. ${ }^{35}$

More recently, several authors observed increased activities of VIP, SP and NOS during inflammatory responses of pigs against Schistosoma japonicum ${ }^{36,37}$ or Brachyspira hyodysenteriae. ${ }^{38}$

Our recent studies have demonstrated distribution and quantitative patterns of lymphoid and myeloid cell subsets within jejunal/ileal mucosae of weaned (4-week-old) pigs following the immunization with either adjuvanted or nonadjuvanted experimental vaccines against porcine postweaning colidiarrhea/colienterotoxemia. ${ }^{39,40}$ Also, we have performed identification, localization and morphometric analysis of antigen sampling microfold (M) cells in the ileal epithelium of weaned pigs as the entry portal for both enteric pathogens and mucosally delivered vaccines such as an experimental Escherichia coli vaccine expressing F4ac fimbrial antigens. ${ }^{41}$ In an attempt to further contribute to understanding the innate mechanisms of intestinal immunity and potentials of its exogenous immunomodulation in developing pigs, we have performed immunohistological identification/localization of immunomodulating neuropeptides VIP and SP and enzyme NOS as well as histomorphometric analyses of their secretion and incidence/density of respective nerve fibers during postnatal ontogenesis, in order to assess the role of these molecules involved in the maturation of porcine IMIS. The age-dependent kinetics and intensity of release of VIP, SP and NOS were also demonstrated in the samples of jejunum and ileum from conventionally reared pigs.

\section{Materials and Methods}

\section{Pigs}

Age-dependent identification/localization of porcine small intestinal neuropeptides (VIP and SP) and NOS, and intensity of their release were analyzed by immunohistology/ histomorphometry in the samples of jejunum/ileum from total of 40 conventionally reared pigs (crossbreds of Swedish Landrace, Yorkshire and Pietren) of both sexes, aged from 0 to 49 days (Table 1).

During experimental period of 7 weeks the pigs were kept under intensive rearing conditions in separate pens (in accordance to their age group either in farrowing or nursery units) of farm facilities and fed ad libitum. The pigs were clinically observed and bacteriologically screened as described earlier ${ }^{39,40}$ and remained healthy during the experimental period.

\section{Immunohistology and histomor- phometry}

The samples of the small intestine were obtained from 5 pigs per age group at $0,7,14$, $21,28,35,42$ and 49 days of age and processed for immunohistological staining. A standard peroxidase-antiperoxidase (PAP) technique was performed for detection of neuropeptides (VIP and SP) and NOS in the tissue sections of jejunum/ileum by labeling reactions using primary antibodies (Table 2).

Quantitative assessment of the intensity of the reactions to anti-SP, - VIP or - NOS $\mathrm{mAbs} / \mathrm{pAbs}$, respectively, was performed with computerized image analysis using light

Table 1. The pigs used for immunohistological demonstration of the small intestinal neuropeptides (VIP and SP) and enzyme (NOS) during early and late postnatal period.

\begin{tabular}{lcc} 
Postnatal period/ $_{\text {category of pigs }}{ }^{\circ}$ & Days of age & Diet \\
Early/suckling pigs & & Milk + commercial prestarter feed \\
& 7 & mixture fed ad libitum from Day 7 \\
& 4 & \\
& 21 & \\
Late/weaned pigs & 28 & Commercial starter feed mixture fed \\
& 35 & ad libitum from Day 28 \\
& 42 & \\
\hline
\end{tabular}

${ }^{\circ}$ Groups comprised 5 pigs each.
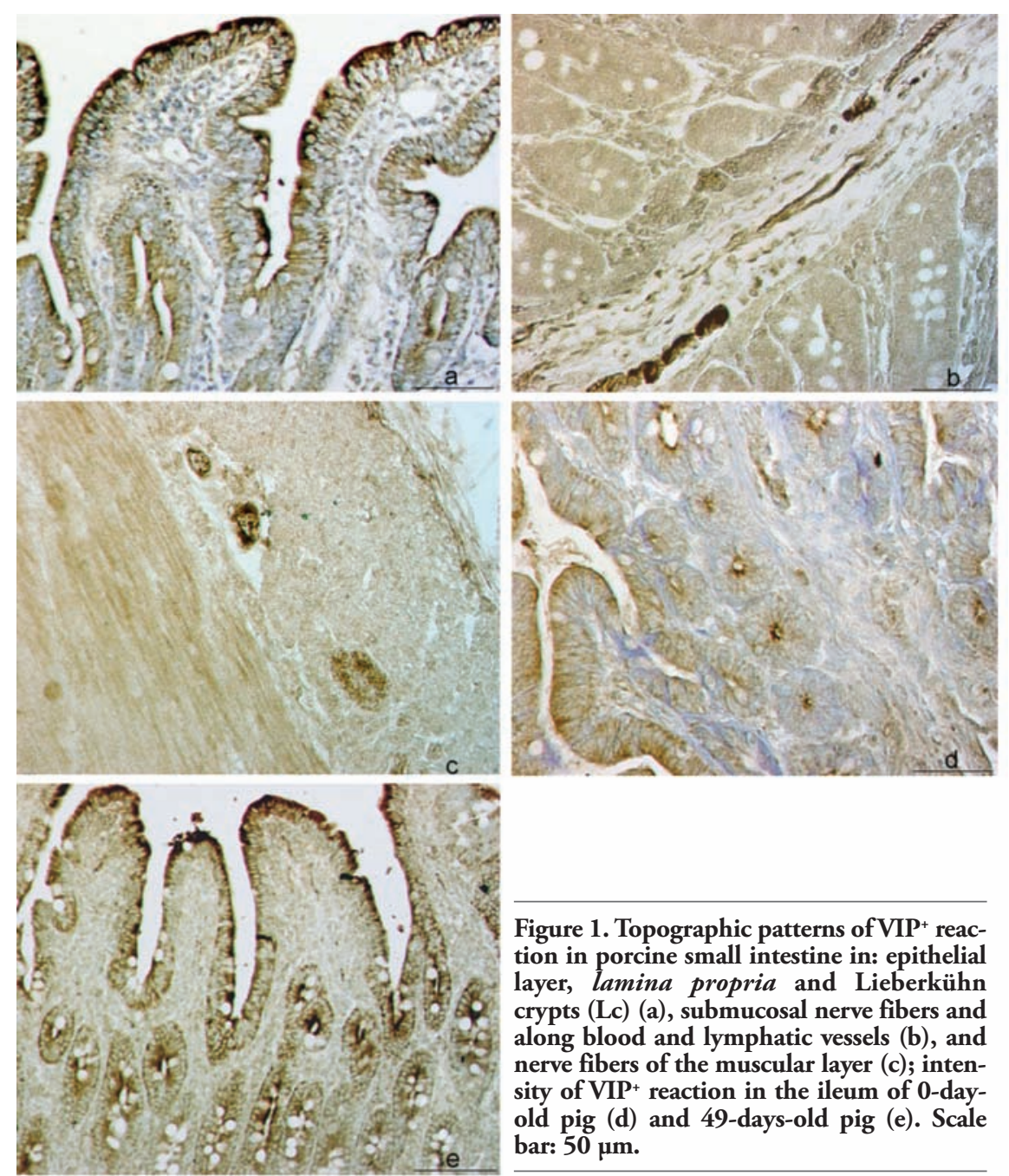

Figure 1. Topographic patterns of VIP ${ }^{+}$reaction in porcine small intestine in: epithelial layer, lamina propria and Lieberkühn crypts $(\mathrm{Lc})(\mathrm{a})$, submucosal nerve fibers and along blood and lymphatic vessels (b), and nerve fibers of the muscular layer (c); intensity of $\mathrm{VIP}^{+}$reaction in the ileum of 0-dayold pig (d) and 49-days-old pig (e). Scale bar: $50 \mu \mathrm{m}$. 
microscope NIKON ECLIPSE - E600 with NIKON DXM 1200 digital camera and LUCIA G 4.8 software. The intensity of reactions to VIP, SP and NOS release was measured in 4 randomly selected areas on 2 samples of jejunum/ileum from each pig per group.

\section{Statistical analyses}

Sperman rank order correlation (rs) test was applied to analyze the relationship between days of age and intensity of the reactions to VIP, SP and NOS according to Roemer Orphal scale as examined/measured in the respective samples of jejunum/ileum from the experimental pigs.

\section{Results}

Differential distribution/intensity patterns of VIP, SP and NOS reactions in the small intestine of neonatal (0-day-old) and weaned (49-day-old) pigs are shown in Figures 1, 2 and 3 (localization/distribution) or Figure 4 (intensity), respectively.

$\mathrm{The} \mathrm{VIP+}^{+}$reaction was prevalently visible in the epithelial layer, lamina propria and Lc but also in the nerve fibers of submucosa and along blood and lymphatic vessels (Figure $1 \mathrm{a}-$ c). The reaction was more intense in the ileum of 49-day-old pig as compared to that of 0 -dayold pig (Figure $1 \mathrm{~d}, \mathrm{e}$ ). The $\mathrm{SP}^{+}$fibers were regularly distributed along enteric neurons in the muscular layer of the ileum regardless the age of pigs (Figure $2 \mathrm{a}, \mathrm{b}$ ). The reaction to NOS was demonstrated in both mucosa and submucosa of ileum and jejunum and in the ileal PP. We have found $\mathrm{NOS}^{+}$blood vessels, particular neurons and nerve fibers in the submucosa and muscular layer of the small intestine (Figure 3 $\mathrm{a}-\mathrm{c}$ ). The intensity of reaction was more pronounced inside the follicles of PP and in the epithelial layer of 0-day-old pig ileum (Figure $3 d)$. In the jejunum of 49-days-old pig the intensity of epithelial reaction was very strong and we have also observed numerous $\mathrm{NOS}^{+}$ cells inside the Lc (Figure 3e).

Age-dependent kinetics and intensity of VIP, SP and NOS reactions in the mucosa of jejunum/ileum from pigs during early (0-21 days of age) and late (28-49 days of age) postnatal ontogeny are presented in Figure 4 (a,c). The release of tested molecules was scored as: 1 = weak, 2 = moderate or 3 = strong and the results were expressed as the mean values for each age group of pigs. The values obtained by Sperman rank order correlation test (rs) between days of age of pigs and intensity of the reactions in jejunal/ileal mucosa to VIP $\left(r_{s}=0.97 / 0.95\right)$, SP $\left(r_{s}=0.97 / 0.97\right)$ and NOS $\left(r_{s}=0.98 / 0.95\right)$, respectively, showed complete
Table 2. Monoclonal (mAb) and polyclonal (pAb) antibodies used for immunohistological demonstration of porcine intestinal neuropeptides (VIP, SP) and enzyme (NOS).

\begin{tabular}{lllll} 
Tlarget molecule & Specificity & Antibody & Isotype & Source \\
SP & Rat & mAb to C-terminal region of SP & IgG & Abcam \\
NOS & Rabbit & pAb reactive with NOS & IgG & Abcam \\
\hline VIP & Rabbit & $\begin{array}{l}\text { pAb reactive with peptide } \\
\text { histidine isoleucine }\end{array}$ & IgG & Abcam \\
& & & \\
\hline
\end{tabular}

${ }^{\circ} \mathrm{N}$-terminal cleavage product of VIP.

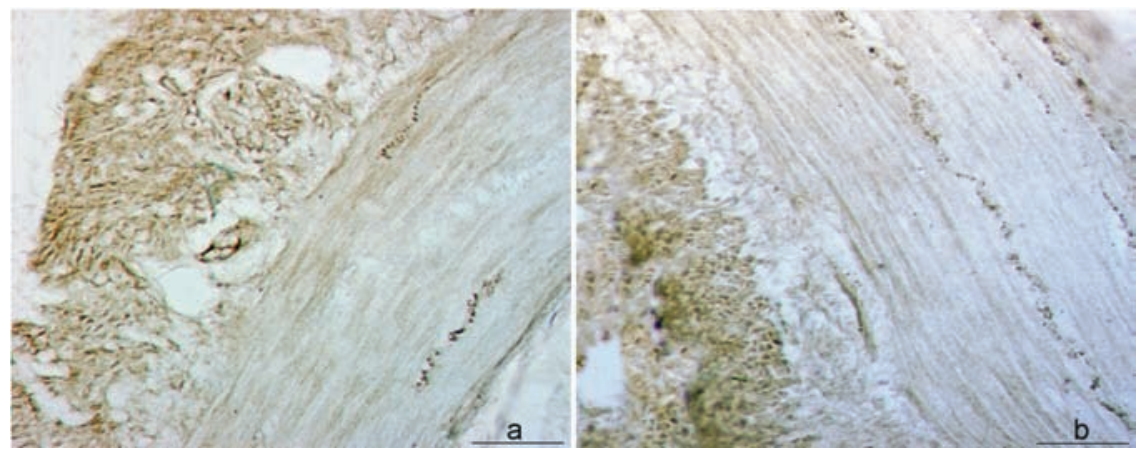

Figure 2. Topographic patterns of $\mathrm{SP}^{+}$nerve fibers along enteric neurons within muscular layer of the ileum of 0-day-old pig (a) or 49-days-old pig (b). Scale bar: $50 \mu \mathrm{m}$.
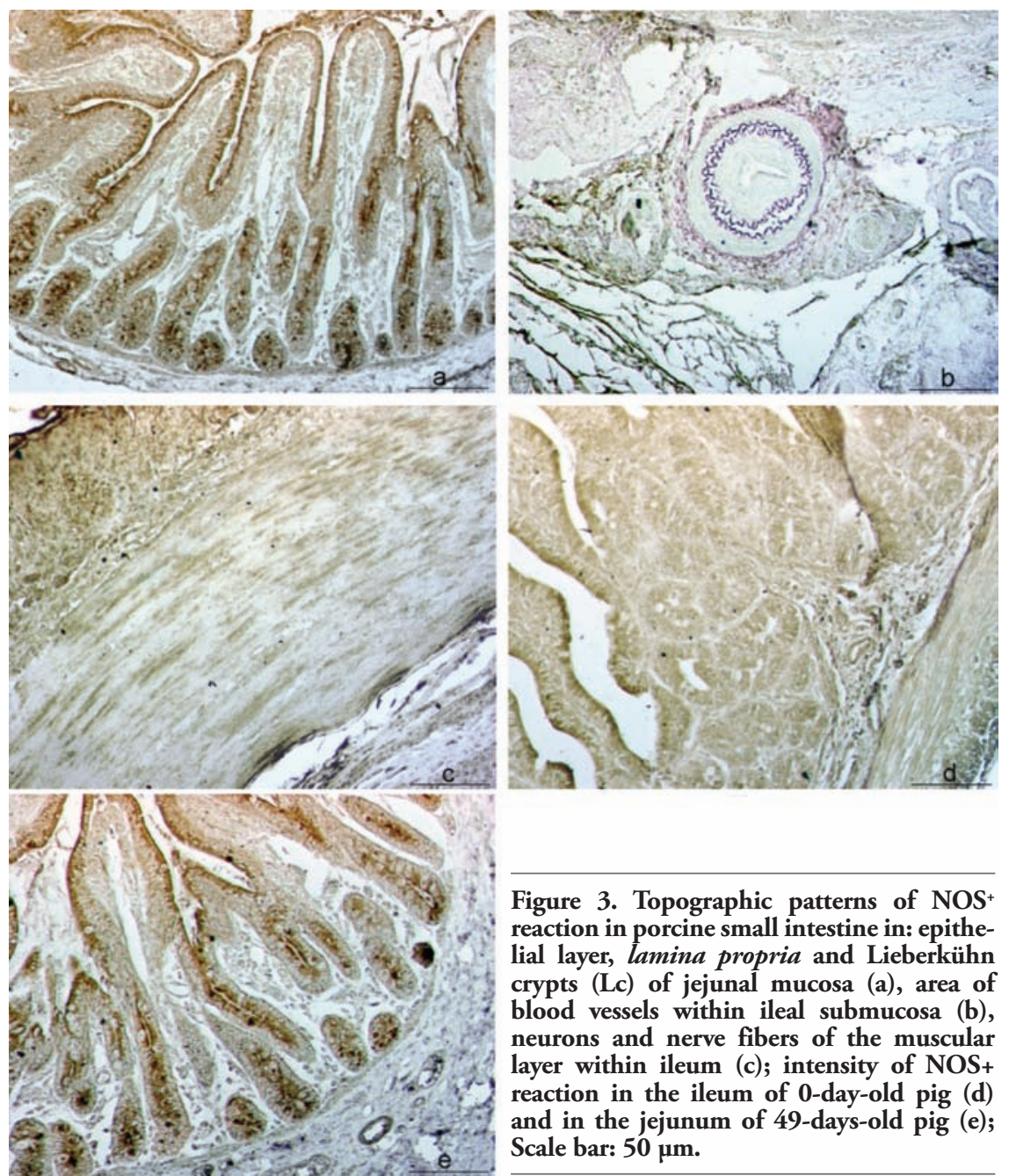

Figure 3. Topographic patterns of NOS reaction in porcine small intestine in: epithelial layer, lamina propria and Lieberkühn crypts (Lc) of jejunal mucosa (a), area of blood vessels within ileal submucosa (b), neurons and nerve fibers of the muscular layer within ileum (c); intensity of NOS+ reaction in the ileum of 0 -day-old pig (d) and in the jejunum of 49-days-old pig (e); Scale bar: $50 \mu \mathrm{m}$. 
positive correlations $(\mathrm{P}<0.05)$ according to Roemer Orphal scale (Figure 4 a,c).

Quantitative patterns of $\mathrm{SP}^{+}, \mathrm{VIP}^{+}$and NOS fibers/release, respectively, showed that intensity of their reactions gradually increases with age, except during a short period of stagnation

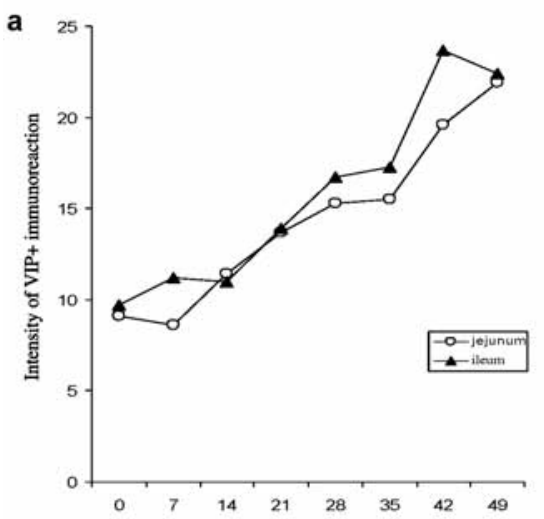

b

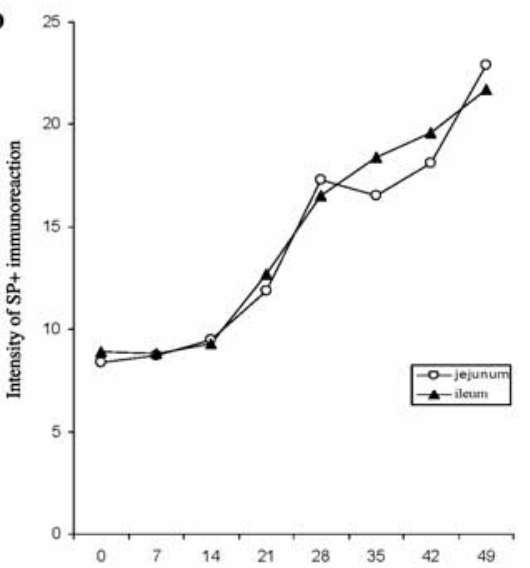

c

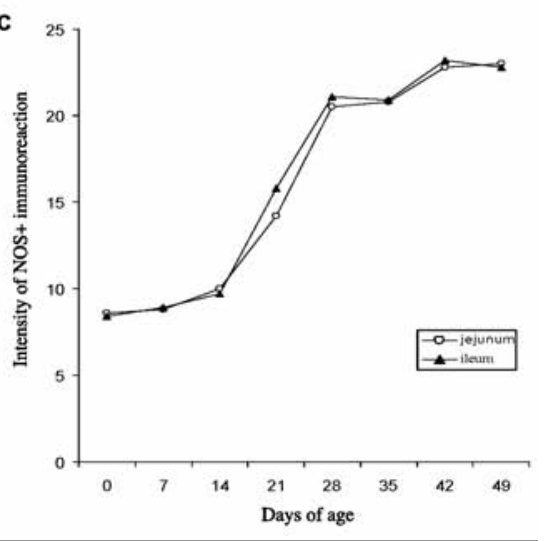

Figure 4. The kinetics and intensity of reaction to neuropeptides VIP (a) and SP (b) and enzyme NOS (c) in the mucosa of jejunum (VIP $r_{s}=0.97$; SP $r_{s}=0.97$; NOS $r_{s}=0.98$ ) and ileum (VIP $r_{\mathrm{s}}=0.95 ;$ SP $r_{\mathrm{s}}=0.97$; NOS $r s=0.95)$ of pigs $(N=5)$ aged from 0 to 49 days; the correlations between age of pigs (independent variable) and intensity of reactions to VIP, SP and NOS (dependent variable) in their small intestinal specimens were positive at $\mathrm{P}<0.05$, respectively. after weaning (at 28 days of age), which is usually accompanied with severe stressful events, reaching the highest values in the pigs aged between 42 and 49 days.

\section{Discussion}

It is well established that porcine IMIS continually balance effector and regulatory functions in the response to antigens encountered through molecular interactions between neuro-endocrine and immune cells. The immunomodulating neurotransmitters, such as VIP and SP, and enzyme NO are well known molecules that participate in these interactions during the immune responses to vast variety of intraluminal antigens and their products operating within the small intestinal mucosal sites. Recently, Kaleczyc et al. ${ }^{38}$ investigated potential interrelationships between immune and neural elements of PP in normal pigs and in the pigs experimentally infected with $B$. hyodysenteriae and suffering from swine dysentery. The obtained results demonstrated reactivity of nerve fibers with antibodies specific for VIP and SP in the interfollicular region and peripheral areas of the PP lymphoid follicles. The study revealed increased levels of SP in the infected pigs, but concentrations of VIP remained similar in both groups of pigs. The authors concluded that experimentally induced swine dysentery, in addition to the large intestine, affected neuroimmunomodulatory processes in the ileal PP, and that SP may play a specific role in this neuroimmune crosstalk. Forsgren et al. ${ }^{42}$ have observed that SPimmunoreactive nerve fibers were more numerous in the mucosa exposed to the radiotherapy and that the SP receptors were more frequent on immunoreactive polymorphonuclear leukocytes residing mucosa, which strongly suggest that SP is involved in the inflammatory processes that occur in response to therapeutic irradiation. Other group of authors $^{43}$ observed changes in SP receptor expression during the chronic intestinal inflammation and suggested that SP receptors are a potential target for therapeutic regulation of the inflammatory responses. Also, Höckerfelt et al. ${ }^{44}$ observed an interaction between the SP-containing nerve fibers and mast cells in the irradiation provoked tissue responses in duodenum of rat. By using another model of the experimental infection, Balemba et $a l .{ }^{36}$ suggested that the alterations in VIP and SP immunoreactivities correlate to pathological lesions and severity of inflammation in the large intestine of pigs infected with $S$. japonicum. They also observed the neuronal NOS activity during granulomatous inflammation in the colon and caecum of pigs infected with $S$. japonicum..$^{37}$ More recent investigations of the involvement of neuroepithelial communication in the regulation of interactions between the IMIS and intraluminal bacteria, such as Salmonella enteritica and $E$. coli will provide novel insights into the mechanisms underlying bacterial colonization and pathogenesis at mucosal surfaces as well as of therapeutic potentials of neurotransmitters in inflammatory diseases. ${ }^{45}$

Unlike such experimental, and probably naturally occuring infections, the exogenous specific and/or nonspecific immunomodulation (applied as prophylactic and/or therapeutic approaches, respectively) of cellular elements of porcine IMIS by adjuvanted/nonadjuvanted vaccine candidate $E$. coli strains that we have performed, ${ }^{39,40}$ is complex concept in scientific terms because there is the necessity to balance immunostimulation against excessive activation of these cells which is usually damaging and growth-inhibiting. Thus, in this study we have attempted to determine incidence and potential role of tested molecular elements (VIP, SP and NOS) operating within porcine IMIS as endogenous immunomodulating agents that may participate in either protective or tolerogenic immune responses, particularly during early ontogeny (from birth to 7 weeks of age) of conventionally reared pigs.

By qualitative and quantitative analyses of these immunomodulating molecules involved in the innate and adoptive mucosal immune responses within porcine small intestine we have demonstrated their localization/distribution and sites of their pronounced secretion in the IMIS during postnatal ontogenesis as determined by intensity of their release, i.e. reactions within tissue microenvironments of jejunum/ileum in developing pigs.

In summary, we have observed that: i) the $\mathrm{VIP}^{+}$reaction was visible in epithelial layer, lamina propria and Lc, but also in submucosal nerve fibers and along blood and lymphatic vessels; ii) the $\mathrm{SP}^{+}$fibers were distributed along enteric neurons in muscular layer. Both muscular layers contained thin SP-reactive nerve fibers parallel to the muscle fibers. Lamina propria, lamina muscularis mucosa and submucosa also contained some SP-reactive neurons and quite a few SP-reactive fibers; iii) the $\mathrm{NOS}^{+}$reaction was demonstrated in mucosa, submucosa and muscular layer (including blood vessels, neurons and nerve fibers) of ileum/jejunum and in the ileal PP. The reaction was more intense in the epithelial layer, and abundant $\mathrm{NOS}^{+}$cells were observed inside the Lc and the PP; iv) the intensity of reactions produced by tested molecules, and thus their release, gradually increased with age with exception of a short period of retardation at 4 weeks of age, reaching highest values between 6 and 7 weeks of 
age; v) age-dependent kinetics and intensity of VIP, SP and NOS reactions in the mucosae of jejunum/ileum of experimental pigs were statistically confirmed as significant $(\mathrm{P}<0.05)$ by Sperman rank order correlation test indicating that all three tested immunomodulating agents play significant roles in establishing immunoregulatory mechanisms within porcine gut mucosa.

In general, current study showed that postnatal development of porcine IMIS is accompanied by a substantial increase in secretion of neuropeptides/enzyme tested which obviously participate as endogenous immunomodulators in the functional maturation of immunoregulatory/bactericidal potentials of the gut immune defense mechanisms in young pigs. Hence, such potentials of these molecular elements of porcine IMIS should be also monitored when an exogenous immunmodulation is applied to enhance defence of intestinal mucosal surfaces of weaned pigs against enteric pathogens

\section{References}

1. Rothkötter HJ, Sowa E, Pabst R. The pig as a model of developmental immunology. Hum Exp Toxicol 2002;21:533-6.

2. Bienenstock J, Croitoru K, Ernst PB, Stead RH, Stanisz A. Neuroendocrine regulation of mucosal immunity. Immunol Invest 1989;18:69-76.

3. Theodorou V, Fioramonti J, Bueno L. Integrative neuroimmunology of the digestive tract. Vet Res 1996;27:427-42.

4. Kimata H, Fujimoto M. Vasoactive intestinal peptide specifically induces human IgA1 and IgA2 production. Eur J Immunol 1994;24:2262-5.

5. Delgado M, Abad C, Martinez C, Juarranz MG, Arranz A, Gomariz RP, et al. Vasoactive intestinal peptide in the immune system: potential therapeutic role in inflammatory and autoimmune diseases. $\mathrm{J}$ Mol Med 2002;80:16-24.

6. De la Fuentes M, Delgado M, Gomariz RP. VIP modulation of immune cell function. Adv Neuroimmunol 1996;6:75-91.

7. Delgado M, De la Fuente M, Martinez C, Gomariz RP. Pituitary adenylate cyclaseactivating polypeptides (PACAP27 and PACAP38) inhibit the mobility of murine thymocytes and splenic lymphocytes: comparison with VIP and implication of cAMP. J Neuroimmunol 1995;62:137-46.

8. Delgado M, Munoz-Elias EJ, Gomariz RP, Ganea D. Vasoactive intestinal peptide and pituitary adenylate cyclase-activating polypeptide prevent inducible nitric oxide synthase transcription in macrophages by inhibiting NF-kB and IFN regulatory factor 1 activation. J Immunol 1999;162:4685-96.

9. Delgado M, Munoz-Elias EJ, Gomariz RP, Ganea D. VIP and PACAP inhibit IL-12 production in LPS-stimulated macrophages. Subsequent effect on IFNY synthesis by T cells. J Neuroimmunol 1999;96:167-81.

10. Delgado M, Pozo D, Martinez C, Leceta J, Calvo JR, Ganea D, et al. Vasoactive intestinal peptide and pituitary adenylate cyclase-activating polypeptide inhibit endotoxin-induced TNF- $\alpha$ production by macrophages: in vitro and in vivo studies. J Immunol 1999;162:2358-67.

11. Martinez C, Delgado M, Pozo D, Leceta J, Calvo JR, Ganea D, et al. Vasoactive intestinal peptide and pituitary adenylate cyclase-activating polypeptide modulate endotoxin-induced IL-6 production by murine peritoneal macrophages. J Leukoc Biol 1998;63:591-601.

12. Delgado M, Munoz-Elias EJ, Gomariz RP, Ganea D. Vasoactive intestinal peptide and pituitary adenylate cyclase-activating polypeptide enhance IL-10 production by murine macrophages: in vitro and in vivo studies. J Immunol 1999;162:1707-16.

13. Delgado M, Abad C, Martinez C, Leceta J, Gomariz RP. Vasoactive intestinal peptide prevents experimental arthritis by downregulating both autoimmune and inflammatory components of the disease. Nat Med 2001;7:563-8.

14. Said SI, Mutt V. Polypeptide with broad biological activity: isolation from small intestine. Science 1970;169:1217-8.

15. Ekblad E, Winther C, Ekman R, Hakanson R, Sundler F. Projections of peptide-containing neurons in rat small intestine. Neuroscience 1987;20:169-88.

16. Pernow B. Substance P. Pharmacol Rev 1983;35:85-141.

17. Felten DL, Felten SY, Carlson SL, Olschowka JA, Livnat S. Noradrenergic and peptidergic innervation of lymphoid tissue. J Immunol 1985;135:1180-6.

18. Popper P, Mantyh CR, Vigna SR, Maggio JE, Mantyh PW. The localization of sensory nerve fibers and receptor binding sites for sensory neuropeptides in canine mesenteric lymph nodes. Peptides 1988;9:257-67.

19. Lorton D, Bellinger DL, Felten SY, Felten DL. Substance P innervation of spleen in rats: nerve fibers associate with lymphocytes and macrophages in specific compartments of the spleen. Brain Behav Immun 1991;5:29-40.

20. Bar-Shavit Z, Goldman R, Stabinsky Y, Gottlieb P, Fridkin M, Teichberg VI, et al. Enhancement of phagocytosis - a newly found activity of substance $P$ residing in its N-terminal tetrapeptide sequence. Biochem Biophys Res Commun 1980;
94:1445-51.

21. Stead RH, Tomioka M, Quinonez G, Simon GT, Felten SY, Bienenstock J. Intestinal mucosal mast cells in normal and nematode-infected rat intestines are in intimate contact with peptidergic nerves. Proc Natl Acad Sci USA 1987;84:2975-9.

22. Bost KL, Pascual DW. Substance P: a lateacting B lymphocyte differentiation co-factor. Am J Physiol 1992;262:537-45.

23. Cook GA, Elliott D, Metwali A, Blum AM, Sandor M, Lynch R, Weinstock JV. Molecular evidence that granuloma T lymphocytes in murine Schistosomiasis mansoni express an authentic substance $P$ (NK-1) receptor. J Immunol 1994;152: 1830-5.

24. Pascual DW, Kiyono H, McGhee JR. The enteric nervous and immune system: interactions for mucosal immunity and inflammation. Immunomethods 1994;5:5672.

25. Pascual DW, Kiyono H, McGhee JR. Mucosal immunity: molecular and cellular aspects of immune protection to enteric infections. In: L.P. Paradise, M. Bendinelli and H. Friedman (eds.) Enteric infection and immune responses. New York, Plenum Publishing, 1996: p. 15-35.

26. Parsons AM, Seybold VS, Chandan R, Vogt $\mathrm{J}$, Larson AA, Murray CR, et al. Neurokinin receptors and mucosal ion transport in porcine jejunum. J Pharmacol Exp Ther 1992;261:1213-21.

27. Brown DR, Parsons AM, O'Grady SM. Substance $P$ produces sodium and bicarbonate secretion in porcine jejunal mucosa through an action on enteric neurons. J Pharmacol Exp Ther 1992;261: 1206-13.

28. Konn HW, Pothoulakis C. Immunomodulatory properties of substance P. The gastrointestinal system as a model. Neuroendocrine and immune crosstalk. Ann NY Acad Sci 2006;1088:23-40.

29. Bogers JJ, Timmermans JP, Scheuermann DW, Pelckmans PA, Mayer B, van Marck EA. Localization of nitric oxide synthase in enteric neurons of the porcine and human ileocaecal junction. Ann Anat 1994;176: 131-5.

30. Grozdanovic Z, Brüning G, Baumgarten HG. Nitric oxide-a novel autonomic neurotransmitter. Acta Anat 1994;150:16-24.

31. Barbieris M, Timmermans JP, Scheuermann DW, Adriaensen D, Mayer B, De GroodtLasseel MHA. Distribution and morphological features of nitrergic neurons in the porcine large intestine. Histochemistry 1993;100:27-34.

32. Matini P, Faussone-Pelegrini MS, Cortesini C, Mayer B. Vasoactive intestinal polypeptide and nitric oxide distribution in 
the enteric plexuses of the human colon: an histochemical study and quantitative analysis. Histochemistry 1995;103:415-23.

33. Dignass AU, Podolsky DK, Rachmilewitz D. NOx generation by cultured small intestinal epithelial cell restitution: central role of transforming growth factor $\beta$. Gastroenterology 1995;105:1323-32.

34. Meyer TA, Tioa GM, James JH, Noguchi Y, Ogle CK, Fischer JE, et al. Nitric oxide inhibits LPS-induced IL-6 production in enterocytes. J Surg Res 1995;58:570-5.

35. Ogra PL, Mestecky J, Lamm ME, Strober W, Bienenstock J, McGhee JR. Mucosal Immunology, 2nd ed. New York, Academic Press, 1999.

36. Balemba OB, Semuguruka WD, HaySchmidt A, Johansen MV, Dantzer V. Vasoactive intestinal peptide and substance P-like immunoreactivities in the enteric nervous system of the pig correlate with the severity of pathological changes induced by Schistosoma japonicum. Int $\mathrm{J}$ Parasitol 2001;31:1503-14.

37. Balemba OB, Mortensen K, Semuguruka WD, Hay-Schmidt A, Johansen MV, Dantzer V. Neuronal nitric synthase activity is increased during granulomatous inflammation in the colon and caecum of pigs infected with Schistosoma japonicum. Autonomic Neuroscience 2002;99:112.

38. Kaleczyc J, Podlasz P, Winnicka A, Wasowicz W, Sienkiewicz W, Zmudzki J, et al. Characterization of autonomic nerve markers and lymphocyte subsets in the Ileal Peyer's Patch of pigs infected experimentally with Brachyspira hyodysenteriae. J Comp Path 2010;143:248-257.

39. Kovšca Janjatović A, Lacković G, Božić F, Špoljarić D, Popović M, Valpotić H, et al. Histomorphometric characteristics of immune cells in small intestine of pigs perorally immunized with F18ac+ nonenterotoxigenic E. coli vaccinal strain. Eur J Histochem 2009; 53:e23.

40. Kovšca Janjatović, A, Lacković G, Božić F, Kezić D, Popović M, Valpotić H, et al. Histomorphometric evaluation of intestinal cellular immune responses in pigs immunized with live oral F4ac+ nonenterotoxigenic E. coli vaccine against postweaning colibacillosis. Eur. J Histochem 2010;54:e4.

41. Valpotić H, Kovšca Janjatović A, Lacković G, Božić F, Dobranić V, Valpotić I, et al. Increased number of intestinal villous $M$ cells in levamisole - pretreated weaned pigs experimentally infected with F4ac+ enterotoxigenic Escherichia coli strain. Eur J Histochem 2010;54:e18.

42. Forsgren S, Höckerfelt U, Norrgård Ö, Henriksson R, Franzen L. Pronounced substance $\mathrm{P}$ innervation in irradiation-induced enteropathy - a study on human colon. Regul Pept 2000;88:1-13.

43. ter Beek WP, Biemond I, Muller ESM, van den Berg M, Lamers CBHW. Substance P receptor expression in patients with inflammatory bowel disease. Determination by three different techniques, i.e., storage phosphor autoradiography, RTPCR and immunohistochemistry. Neuropeptides 2007;41:301-6.

44. Höckerfelt U, Franzen L, Forsgren S. Substance $\mathrm{P}$ (NK1) receptor in relation to substance $P$ innervation in rat duodenum after irradiation. Regul Pept 2001;98:11526.

45. Green BT, Brown DR. Interactions between bacteria and the gut mucosa: Do enteric neurotransmitters acting on the mucosal epithelium influence intestinal colonization or infection? In: M. Lyte and P.P.E. Freestone (eds.) Microbial endocrinology. New York, Springer, 2010: p. 89-109. 